\title{
Correction to: Letter to the editor regarding "safety of safety evaluation of pesticides: developmental neurotoxicity of chlorpyrifos and chlorpyrifos-methyl" by Mie et al. (environmental health. 2018. 17:77)
}

\author{
Daland R. Juberg ${ }^{1 *}$, Alan M. Hoberman², Sue Marty ${ }^{3}$, Catherine A. Picut ${ }^{4}$ and Donald G. Stump ${ }^{5}$
}

\section{Correction to: Environmental Health \\ https://doi.org/10.1186/s12940-019-0454-x}

Following publication of the original article [1], the authors reported a change in the 'Competing interests' section as described below:

'Competing interests' in the original article.

The authors declare that they have no competing interests. All willingly contributed their knowledge and perspective on the conduct and interpretation of two toxicology studies for chlorpyrifos and chlorpyrifosmethyl, respectively.

Revised 'Competing interests'.

At the time of submission, Drs. Juberg and Marty were employed by Dow AgroSciences LLC and The Dow Chemical Company, respectively. Dow AgroSciences is the primary registrant of chlorpyrifos and chlorpyrifos-methyl in the U.S., and The Dow Chemical Company is a manufacturer of both chemicals. All other co-authors are not affiliated with either company. All co-authors willingly contributed their knowledge and perspective on the conduct and interpretation of two toxicology studies for chlorpyrifos and chlorpyrifos-methyl.

\section{Author details}

${ }^{1}$ Human Health Science Policy, Corteva Agrisciences, Indianapolis, IN, USA. ${ }^{2}$ Global Developmental, Reproductive and Juvenile Toxicology, Charles River Laboratories, Horsham, PA, USA. ${ }^{3}$ Toxicology \& Environmental Research and Consulting, The Dow Chemical Company, Midland, MI, USA. ${ }^{4}$ Charles River Laboratories, Durham, NC, USA. ${ }^{5}$ Charles River Laboratories, Ashland, OH, USA.
Published online: 14 May 2019

\section{Reference}

1. Juberg, et al. Environmental health letter to the editor regarding "safety of safety evaluation of pesticides: developmental neurotoxicity of chlorpyrifos and chlorpyrifos-methyl" by Mie et al. (environmental health. 2018. 17:77). Environ Health. https://doi.org/10.1186/s12940-019-0454-x.

* Correspondence: drjuberg@dow.com

${ }^{1}$ Human Health Science Policy, Corteva Agrisciences, Indianapolis, IN, USA

Full list of author information is available at the end of the article

(c) The Author(s). 2019 Open Access This article is distributed under the terms of the Creative Commons Attribution 4.0 International License (http://creativecommons.org/licenses/by/4.0/), which permits unrestricted use, distribution, and reproduction in any medium, provided you give appropriate credit to the original author(s) and the source, provide a link to the Creative Commons license, and indicate if changes were made. The Creative Commons Public Domain Dedication waiver (http://creativecommons.org/publicdomain/zero/1.0/) applies to the data made available in this article, unless otherwise stated. 